\title{
Social Patterning of Screening Uptake and the Impact of Facilitating Informed Choices: Psychological and Ethical Analyses
}

\author{
Rachel Crockett · Timothy M. Wilkinson - Theresa M. Marteau
}

Published online: 28 June 2007

(C) Springer Science+Business Media, LLC 2007

\begin{abstract}
Screening for unsuspected disease has both possible benefits and harms for those who participate. Historically the benefits of participation have been emphasized to maximize uptake reflecting a public health approach to policy; currently policy is moving towards an informed choice approach involving giving information about both benefits and harms of participation. However, no research has been conducted to evaluate the impact on health of an informed choice policy. Using psychological models, the first aim of this study was to describe an explanatory framework for variation in screening uptake and to apply this framework to assess the impact of informed choices in screening. The second aim was to evaluate ethically that impact. Data from a general population survey $(n=300)$ of beliefs and attitudes towards participation in diabetes screening indicated that greater orientation to the present is associated with greater social deprivation and lower expectation of participation in screening. The results inform an explanatory framework of social patterning of screening in which greater orientation to the present focuses attention on the disadvantages of screening, which tend to be immediate, thereby reducing participation. This framework suggests that an informed choice policy, by increasing the salience of possible harms of screening, might reduce uptake of screening more in those who are more deprived and orientated to the present. This possibility gives rise to an apparent dilemma where an ethical decision must be made between greater choice and avoiding health inequality. Philosophical perspectives on choice and inequality are used to point to some of the complexities in assessing whether there really is such a dilemma and if
\end{abstract}

R. Crockett $(\bowtie)$. T. M. Marteau

Psychology Department (at Guys'), Section of Health Psychology, King's College London,

5th Floor Thomas Guy House, Guy's Campus, London SE1 9RT, UK

e-mail: rachel.a.crockett@kcl.ac.uk

T. M. Wilkinson

School of Population Health, University of Auckland, Private Bag 92019, Auckland, New Zealand e-mail: m.wilkinson@auckland.ac.uk 
so how it should be resolved. The paper concludes with a discussion of the ethics of paternalism.

Keywords Screening · Public health approach · Informed choice ·

Autonomy · Paternalism · Health inequality · Utilitarianism · Egalitarianism .

Prioritarianism

\section{Introduction}

\section{Approaches to Screening}

A major component of current public health strategy is the provision of screening programmes to allow prevention and early treatment of serious disease. A characteristic of screening is that it involves the possibility of immediate harm in return for the possibility of future benefit. For example breast screening with mammography has a number of substantial possible immediate harms [26, 38, 50]. In 2001 five percent of mammography screens in the US gave a false positive result leading to further testing [53]. Even when further tests result in a diagnosis of breast cancer, about 20 percent of the cases identified will be of ductal carcinoma in situ which has an uncertain course without treatment [50]. Many such cancers are not life threatening but, once detected, are usually treated as such [53]. Such treatments are unpleasant and damaging to health and women diagnosed with ductal carcinoma in situ have similar anxiety levels to those with early invasive breast cancer [39]. In contrast, only a small number of people, relative to the total screened, have their lives saved, even over a considerable period of time. Estimates suggest that 2451 women aged between 50 and 59 need to be screened as recommended over a five-year period to save one life [41].

Because only a few cases of disease will be detected within a healthy population, large numbers need to be screened in order to have an impact on overall population health. Thus high uptake of screening has been encouraged by emphasizing the benefits of participation, reflecting a public health approach to screening [27]. Recently, in the UK, there has been a policy change towards promoting informed choices particularly in screening:

There is a responsibility to ensure that those who accept an invitation [to screening] do so on the basis of an informed choice, and appreciate that in accepting an invitation or participating in a programme to reduce their risk of a disease there is a risk of an adverse outcome [32].

One of the factors influencing the move to informed choices has been a concern about patient autonomy [16]. The issue of autonomy has become more salient with the rise of 'patient-centred medicine' in reaction to concerns with traditional medical practice and its emphasis on the role of the health professional in medical decision-making. [37] 


\section{Informed Choice in Screening}

Informed choices have been defined as those based on relevant knowledge, consistent with the decision-maker's values and behaviourally implemented [28]. To make an informed choice participants need information about their personal risks of developing the condition, what having the screening test will be like, accuracy of the test, and what will happen if the screening test is positive [15]. While the place of this information in facilitating informed choices is obvious, the role of values may be less so. People will, however, attach different values to the possible outcomes of screening. For example those who are more and less socially deprived may place a different value on early diagnosis. The consequences of being diagnosed with a serious condition can have very different implications for those who have material resources and those who don't, even within a universal healthcare system. While those who have a high level of material resources can use those resources to ameliorate the impact of a diagnosis of serious illness, for those who are more socially deprived such a diagnosis may bring the prospect of increasing poverty and uncertainty and they might thus prefer to delay knowledge of an illness for as long as possible [24].

There has been no research to describe or evaluate the impact of an informed choice policy in screening. One possible impact is that it will reduce uptake of the screening programme with a greater reduction in some groups, for example those who are more socially deprived and already have lower participation in screening. Such a decline in the uptake of screening could be evaluated negatively as contributing to a decline in the overall health of the population or positively as reflecting an increase in the autonomy of the individual. This paper seeks to describe and evaluate the possible impact of an informed choice policy in screening.

\section{Explaining Screening Uptake}

Uptake of screening is lowest in those who are most socially deprived. This is a consistent finding across different screening programmes and healthcare systems $[20,29,48]$. Lower uptake among the most socially deprived is, at least in part, a consequence of a lack of material resources, such as transport costs to the screening centre. But when the lack of such resources is controlled for in statistical analyses, differences in uptake remain [23]. Psychological characteristics, among other factors, contribute to explaining those differences [48, 52].

One such psychological characteristic might be time orientation. Psychologists suggest that people use information about the timeframe in which an event occurs to process information about the event and to make decisions. However, people's responses to the specific timeframe in which an event might occur, vary. Individuals have preferences for certain timeframes which influence their information processing and evaluation of actions and the possible outcomes of those actions. These preferences are called time orientation.

While a number of different time orientations have been identified [55], evidence for their existence is strongest for two of these, future and present orientation. Those who have high future orientation think more about the future and have an awareness 
of the effects of current actions on future outcomes compared to those with lower future orientation [42]. Future orientation is associated with the practice of healthrelated behaviours, such as physical activity and healthy eating, that might involve immediate cost for possible future gain [22, 25, 34, 42]. Those who have high present orientation think more about immediate outcomes of their behaviour than those who are less present orientated [42]. High present orientation is also associated with a limited sense of control and fatalism about life events [42] and unhealthy behaviours, such as substance abuse, which result in immediate rather than future rewards $[18,42]$. Future and present orientation are largely independent, of one another with each being associated with different patterns of thought and behaviour $[18,56]$.

Because the possible harms of screening are immediate while the possible benefits occur in the future, time orientation may contribute to explaining screening uptake. Increasing information about the possible harms and limited benefits of screening may therefore have a differential impact on those with different time orientations. Given that time orientation and social deprivation are associated $[33,47]$, this effect may vary by social deprivation.

\section{Aims}

The first aim of this study is to describe the possible impact of an informed choice policy on screening uptake by exploring the relationships between social deprivation, present orientation and expectations of participation in screening. The second aim is to evaluate that impact from different ethical perspectives.

\section{Method}

Design

A questionnaire-based descriptive survey.

Sample

A total of 300 participants was recruited. The sample was structured to reflect the English population in terms of age and sex with one third of the sample being drawn from each of the North, South and Midlands of England.

Procedure

Home-based interviews were conducted by a research agency. Questionnaires were completed by interviewers on behalf of participants.

Materials

In the first part of the interview information about diabetes screening, based on that used in previous research [34], was presented to participants (Appendix 1), after which the following measures were completed: 
1. Expectations of participation in screening. The mean response to three items measuring intention to participate in screening was assessed on five-point response scales [34, 35] giving a measure with good reliability (Cronbach's alpha: .85).

2. Time orientation. A brief, nine item version of the Stanford Time Perspective Inventory (Crockett et al. in submission). The Stanford Time Perspective Inventory (STPI) has been extensively validated and used in the study of health behaviour [9, 21, 42, 56]. This brief STPI consists of nine items, measured on five-point rating scales, comprising two subscales with adequate reliability: five items measuring future orientation (Cronbach's alpha: .67) and four items measuring present orientation (Cronbach's alpha: .62).

3. Social deprivation: A brief three item measure asking participants to indicate:

i. Possession of educational qualifications

ii. Home ownership (including having a mortgage).

Those who neither owned their homes nor had any educational qualifications were considered to have the greatest social deprivation (scored as 2); those who either owned their homes or had educational qualifications were considered to have intermediate levels of social deprivation (scored as 1); and, those who both owned their homes and had educational qualifications were considered to have the least social deprivation (scored as 0 ). This measure was derived from our previous research which indicated that individual level measures of social deprivation showed greater associations with psychological characteristics than did neighbourhood measures such as the Indices of Multiple Deprivation (Crockett et al. in preparation).

Analysis

Statistical analyses were conducted using SPSS version 12. Associations between social deprivation, future and present time orientation and expectations of participation in diabetes screening were examined using Spearman's rank correlations.

\section{Results}

The associations between social deprivation, time orientation and expectations of participation in diabetes screening are shown in Table 1.

Future orientation was not significantly associated with social deprivation ( $r=-.067, n=300, P=.247$ ) or with expectations of participation in screening $(r=.054, n=300, P=.349)$. However present orientation was significantly associated with both social deprivation $(r=.245, n=300, P<0.001)$ and expectations of participation in screening $(r=-.265, n=300, P<0.001)$.

Because only present orientation showed associations with social deprivation and expectations of participation in screening, further findings are presented for present orientation only. To illustrate the association between social deprivation, uptake of 
Table 1 Associations between expectations of participation in screening, social deprivation and present orientation (Spearman's rho correlation)

\begin{tabular}{lccc}
\hline & Present orientation & Future orientation & Expectations of diabetes screening \\
\hline Social deprivation & $-.245^{* * *}$ & .067 & $.218^{* * *}$ \\
Present orientation & & $-.301^{* * *}$ & $-.265^{* * *}$ \\
Future orientation & & .054 \\
\hline
\end{tabular}

*** $P<0.001$

${ }^{\text {a }}$ most deprived scored as 0 , intermediate group scored as 1 , least deprived group scored as 2

screening and present orientation, two figures were plotted. Figure 1(a) shows the mean expectation of participation in diabetes screening at each level of deprivation. As social deprivation increases, expectations of participation decrease. A one-point difference between those most and those least deprived indicates a substantial effect of social deprivation on expectations of participation in screening. Figure 1(b) shows the mean expectation of participation between those with high and low levels of present orientation, indicating that those with low present orientation express higher expectations of participating in screening. Figure 1(b) does not indicate such
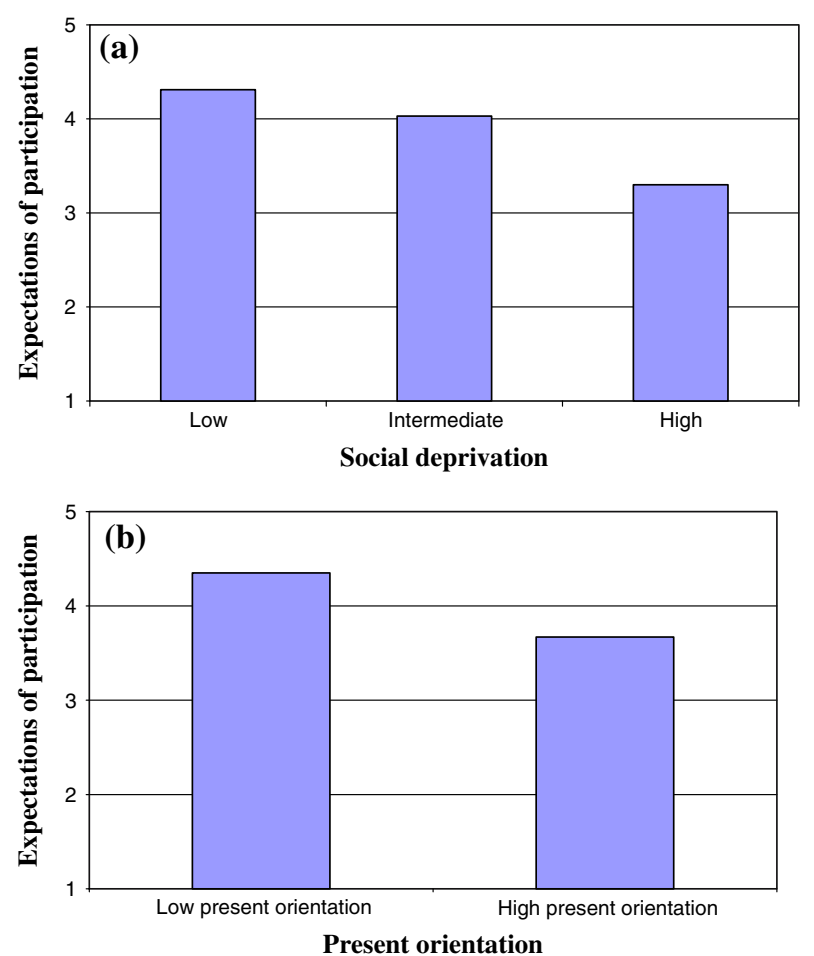

Fig. 1 Expectations of participation in screening and (a) social deprivation, (b) present orientation, High and low present orientation calculated by means of a mean split 
large effects as seen in Fig. 1(a) suggesting that other variables must contribute to the impact of social deprivation and expectations of participation in screening.

Additional analyses using another part of the data set presented here indicate present orientation explains part of the association between social deprivation and uptake (Crockett et al. in submission).

\section{Summary}

The results of this study suggest that present orientation is associated with both social deprivation and with uptake of screening, such that present orientation partially accounts for the relationship between greater social deprivation and lower expectations of participation in screening. The results indicate that psychological factors can contribute to an explanatory framework of screening uptake. This framework suggests that there is an association between social deprivation and present orientation and that decisions about uptake of screening are influenced by the time orientation of those who are invited. This framework further suggests that making the more immediate possible harms of screening more salient, as would happen in an informed choice policy, could reduce uptake of screening in those who are more socially deprived. This framework can be used to identify and evaluate the possible impact of an informed choice policy in screening.

\section{Evaluation}

The Possible Impact of Informed Choices on Inequality

The study results suggest that the implementation of an informed choice policy, which makes salient the possible immediate harms of participation, might lead to decreases in uptake of screening among those who are more socially deprived. This decrease is unlikely to be matched by a similar decrease among those who are less deprived, not only because they are less present orientated but also because evidence suggests that those who are more educated, and typically less deprived, are more aware of the limited benefits of screening programmes [12].

A differential decline in uptake of screening is an issue of particular concern. Those who are more socially deprived already have poorer health [7, 17] and are more likely to develop diabetes and its complications [3, 8]. A reduction in uptake of screening among those who are most deprived might widen the existing gap in physical health between those who are more and less socially deprived, running counter to UK government policy of reducing such inequalities $[10,11]$. If an informed choice policy does reduce the rate of screening of the most deprived, then there appears to be an ethical dilemma. On the one hand, there can be greater choice but at the ethical cost of increased inequality; on the other hand, greater inequality can be avoided, but at the ethical cost of less informed choice. In the rest of this paper, we aim to describe this dilemma more fully and offer some thoughts about how, in the face of it, an informed choice might be evaluated. 
We should say at the start that our aims are limited and that we do not try, nor think it possible, to evaluate an informed choice policy fully in the space available. Our discussion is aimed at those who feel an initial ethical pull both toward reducing inequality and toward informed choice. Among those who feel this pull are the UK government, whose policies are explicitly designed to try to achieve both. Thus we do not aim to persuade those libertarians or elitists who oppose taxationfunded screening programs altogether. Nor do we intend the ethical claims we make to be applicable in all times and places.

In aiming our discussion at those who are attracted both to equality and choice, we do not suggest that the nature of these values is at all obvious. Indeed, one of our major points will be that any evaluation of an informed choice depends on further specification of these values. It might well turn out, as these values are specified, that the dilemma between choice and equality is merely apparent and that a decision between them in the context of screening does not have to be made.

After the ethical characterization of the choice and equality dilemma, we critique a public health and paternalistic approach to screening that is sceptical about the value of choice.

\section{Is There a Dilemma?}

As mentioned, it appears that there is a dilemma for those who value both choice and equality if an informed choice policy reduces the rate of screening of the most deprived without significantly reducing the rates for everybody else. It appears that the health of the most deprived would decline relative to others and thus inequality of health would increase. Whether there is actually a dilemma depends partly on what happens to screening rates in practice, but it also partly depends on the characterization of the ethical values, as we shall now show.

In the first place, it is not obvious, even if there are differential impacts on screening rates, that choice would produce greater inequality of health. While maximizing informed choices might result in decreased physical health, by promoting personal autonomy they might increase psychological well-being. Personal autonomy has been related to two specific psychological constructs [51]: perceived control, which has been linked to positive outcomes including coping, personal adjustment and success or failure in a variety of areas of life [46]; and selfefficacy, which is the sense of having mastery over the action needed to achieve a particular end [4]. Self-efficacy is associated with a number of health-related behaviours including uptake of screening [13, 14, 19, 25]. Those who are more socially deprived are not only disadvantaged in terms of physical health but commonly also have lower levels of positive psychological characteristics, such as self-efficacy, which contribute to an individual's overall well-being and are related to the ability to make autonomous choices in a variety of health and life domains $[5]$.

The point here can be made in two different ways. One is to say that health, as a philosophical concept, is about more than narrowly defined physical health and that the psychological benefits of greater choice for the most deprived are gains in health to them. This leaves it moot whether a reduction in their rates of screening is worse 
for them in terms of their health, and thus moot whether choice increases inequalities in health. A second way, which avoids the complicated conceptual debates about what health is, puts the point as one about the determinants of health. Even on a relatively narrow construal of health as physical health the psychological gains of choice, such as increased sense of control [51], might improve the physical health of the most deprived [1], again leaving it moot whether choice increases inequalities in health.

Even if there is a conflict between choice and equality of health, it does not follow that there is a conflict between choice and the value of equality. Again, whether there is a conflict depends on further specification of the value. There is a large debate in political philosophy called the 'equality of what?' debate [44]. Fundamentally, however health is characterized and however equality is characterized, health would only be one item in the metric of inequality. Suppose that an informed choice policy causes the health of the most deprived to be lower than it would otherwise have been. The policy also causes their choice to go up. Whether the result is to make them worse off than they would otherwise have been is a complicated question that depends on the relative value of health and choice. Possibly the result should be counted as a gain in equality, since it increases the choice of the most deprived, although possibly not. The point here is that, from the viewpoint of equality, concentrating on inequalities in health is concentrating on only part of the picture.

Not only is the evaluation of choice complicated by debates about health and the metric of equality, it is also complicated by debates over how to understand the value of equality. It is possible to give only an incomplete and sketchy account of this here. Consider three views: utilitarianism, prioritarianism, and egalitarianism. Utilitarianism recommends policies that maximize aggregate welfare [45]. It would recommend reducing inequalities of health if this would indeed maximize welfare. Many utilitarians believe that greater equality would maximize welfare [6]. As for the policy of informed choice, utilitarians would recommend it if it led to greater welfare than the alternative and oppose it if it reduced welfare. In the next section, on paternalism, we make some points about the effects of choice on welfare.

Prioritarianism recommends policies that improve the position of the worst off. Prioritarians disagree among themselves about the extent of the priority that should be given to the worst off, for instance whether small gains to the worst off outweigh large gains to everyone else [30, 31]. However prioritarians decide to evaluate gains to the worst off, there is no necessary connection between their view and favouring equality. Improving the position of the worst off might reduce inequalities in health, but it might also increase them [36, 40]. Egalitarians, by contrast, believe that inequality is in itself bad. For them, there is some value in reducing inequality even if it is bad for some and good for no one [49]. This is not to say that egalitarians would, all-things-considered, want greater equality if it produced no gain in anyone's welfare. Their attitude to inequalities would depend on the other values they hold [36].

In the face of this sketch of various positions, it is clear that evaluating any inequality produced by an informed choice policy requires more detail about those effects. That inequality increases does not on its own justify opposing the policy. 
Suppose inequality increases because the most deprived stay the same, on whatever is the right metric for measuring people's positions, but the position of others improves. Utilitarians and prioritarians should endorse the policy. Egalitarians might oppose it but also might not, depending on the other values they hold. Suppose the position of the most deprived goes down and others' positions improve. Egalitarians and prioritarians would probably oppose it, although that might depend on how much the most deprived lose and how much others gain. Utilitarians will weigh up the gains and losses to see what maximizes welfare.

In this section we have pointed out some of the complexities of evaluating the policy of informed choice even if we assume some initial ethical commitment to both choice and equality. In particular, we have shown that the initial statement of the dilemma between choice and equality is too crude, and that there might be no dilemma in the end. In describing the complexities we do not want to suggest that a rationally defensible overall evaluation is impossible, only that it is perhaps more difficult than one might think. In the next section, we continue the theme of complexity by pointing to the for a brisk paternalistic public health approach that says that if choice reduces health it must be bad.

\section{Informed Choice, Public Health, and Paternalism}

If an informed choice policy really does reduce the screening rates of the most deprived — or, indeed, of the general population — then the argument might be made that the policy is ethically wrong because it would increase morbidity and mortality. The argument might be put in terms of public health, that the disease burden of society would increase, or more directly in paternalistic terms, that individuals would be net worse off for having and making the choice not to be screened, and that either way, an informed choice should not be implemented. While we cannot show decisively that this argument is mistaken, this section points to some of the serious difficulties that face it. We should state at the outset that we understand paternalism in the sense commonly used in political philosophy, where an action is paternalistic only if it is both motivated by concern for the target's interests and in some way bypasses the target's own decision-making, for instance by coercing the target or failing to disclose relevant information [54].

Firstly, at the population level any loss of life resulting from an informed choice policy has to be set alongside the negative impacts of a public health approach to screening including death as a consequence of that approach. Emphasizing the benefits of screening results in limited understanding of the harms of screening, including the possibility of false negatives and in turn this leads to an overestimation of the reliability of screening results by both the public and health professionals [38]. This may lead to symptoms of disease being ignored following a negative screening result, delaying diagnosis and treatment [2, 38].

Essentially the same points can be made if the argument is put instead in paternalistic terms, that individuals choose against their best interests when they choose against screening. From the point of view of any given individual facing the choice of whether to undergo screening, not being screened carries a certain risk of morbidity and mortality and so does being screened. Given other costs and benefits 
of screening, it might be quite rationally self-interested for some individuals to decide to undergo screening while others choose against it. It is likely that in many cases those who are more deprived would indeed value increased life expectancy and it would therefore be appropriate to give those from lower socioeconomic groups information about their higher risk of dying from the disease to inform their personal evaluation of the benefits and harms of participation. However, it is also possible that those who are more socially deprived may value increased life expectancy differently to those who are less socially deprived resulting in a preference to delay diagnosis for as long as possible, even if, in the long term this results in a shortened life expectancy [24]. Thus it is much harder than might be thought to show that those who choose against screening must be acting against their better interests.

Moreover, as we pointed out in the previous subsection, the value of autonomous choice can be intertwined with people's interests in that having choices can have psychological, and health-promoting, benefits given perceived control and selfefficacy have been linked to good health $[1,5]$. This is a further reason to doubt that restricting individuals' informed choice would promote their overall welfare.

The argument from the benefits of screening against informed choice, in either public health or paternalistic forms, arguably also undervalues autonomy. For many political philosophers, and people more generally, being able to make choices for oneself is good in itself. The value of informed choice is not simply in the extent to which is allows us to choose what is really in our interests. In other dimensions of life, such a choice of career or partner, many people want to make their own choices even if they are less good at selecting than some disinterested observer [43]. Perhaps these reasons to value informed choice carry over to the choice of screening even if people do sometimes get it wrong.

A persuasive paternalistic argument must show that, given the possibility of an informed choice, the people would tend to choose against their interests and that this would justify denying them the choice. We have not shown that no such argument could be made, but we have tried to show the severity of the difficulties that face it.

\section{Conclusions}

This paper has shown how psychological research can contribute to assessing the possible impact of an informed choice policy on screening uptake. It suggests that an informed choice policy could lead to a decrease in uptake of screening amongst those who are most socially deprived, resulting in decreases in the physical health of this group. From a public health perspective any decrease in physical health is a matter of concern, particularly if that decrease is greater in those who are more socially deprived. From an informed choice perspective such a decrease in uptake could be interpreted as indicating that people are making autonomous choices based not only on good knowledge, but also in line with their own values. Those who are more socially deprived are more present orientated. They therefore value actions that have positive outcomes immediately and thus, once they understand that the benefits of screening are not immediate, may be less likely to participate in the screening programme. 
These results have been evaluated from different philosophical perspectives on health inequality and on choice. This evaluation has not attempted to provide a definitive assessment of whether the introduction of an informed choice policy in screening can be justified in the light of the likely impact on physical health inequalities outcomes across the population. Rather, the evaluation has sought to describe the way in which philosophical approaches to choice and to health inequality can be used to inform further discussions about choosing an informed choice approach to screening over a public health approach.

Acknowledgements RC is funded by a Wellcome Trust Prize Studentship (Grant number: 075319).

\section{Appendix 1}

There are 2 types of diabetes. The most common type of diabetes is called Type 2 diabetes. People who have this type of diabetes are more likely to develop heart disease, stroke, eyesight problems, kidney failure, problems with feet and impotence and their life expectancy is reduced by ten years. The complications of having diabetes can be prevented by controlling diet, increasing activity and by taking tablets prescribed by a doctor.

The chance of developing diabetes increases with age. It is possible for someone to have Type 2 diabetes and not to know it because they show no symptoms and do not feel unwell. The Department of Health estimates that there are between 600,000 and 800,000 people in this country who do not know that they have diabetes. The Department of Health is considering offering people a free screening test for diabetes in the next few years.

The screening test can find some but not all of those who have the early stages of diabetes. Some people find that taking part in screening means that they have to undergo unpleasant and inconvenient procedures. They may also find that they start worrying about diabetes and may have to start taking tablets and changing their lifestyle. Some people find that taking part in screening gives them peace of mind about their health and they also know that their early diagnosis will prevent complications and illness.

\section{References}

1. Adler, N. E., \& Snibbe, A. C. (2003). The role of psychosocial processes in explaining the gradient between socioeconmic status and health. Current Directions in Psychological Science, 12, 119-123.

2. Anderson, C., \& Nottingham, J. (1999). Bridging the knowledge gap and communicating uncertainties for informed consent in cervical cytology screening. Cytopathology, 10, 221-228.

3. Bachmann, M. O., Eachus, J., Hopper, C. D., Davey, Smith, G., Propper, C., \& Pearson, N. J., et al. (2003). Socio-economic inequalities in diabetes complications, control, attitudes and health service use: a cross-sectional study. Diabetes Medicine, 20, 921-929.

4. Bandura, A. (1997). Self efficacy: The exercise of control. New York: WH Freeman and Company.

5. Blacksher, E. (2002). On being poor and feeling poor: Low socioeconomic status and the moral self. Theoretical Medicine and Bioethics, 23, 455-470. 
6. Brandt, R. (1992). Morality Utilitarianism and Rights. Cambridge: Cambridge University Press.

7. Coleman, M. P., Rachet, B., Woods, L. M., Mitry, E., Riga, M., \& Cooper, N., et al. (2004). Trends and socioeconomic inequalities in cancer survival in England and Wales up to 2001. British Journal of Cancer, 90, 1367-1373.

8. Congdon, P. (2006). Estimating diabetes prevalence by small area in England. Journal of Public Health, 28, 71-81.

9. D’Alessio, M., Guarino, A., De Pascalis, V., \& Zimbardo, P. G. (2003). Testing Zimbardo's Stanford Time Perspective Inventory (STPI) - short form - An Italian study. Time \& Society, 12, 333-347.

10. Department of Health (2000). The NHS cancer plan. London: Department of Health.

11. Department of Health. (2002). Tackling health inequalities: Cross-cutting review. London: Department of Health.

12. Dobias, K., Moyer, C., McAchran, S., Katz, S., \& Sonnad, S. (2001). Mammography messages in popular media: implications for patient expectations and shared clinical decision-making. Health Expectations, 4, 131-139.

13. Epel, E., Bandura, A., \& Zimbardo, P. G. (1999). Escaping homelessness: The influences of selfefficacy and time perspective on coping with homelessness. Journal of Applied Social Psychology, 29, 575-596.

14. Ford, J. S., Ostroff, J. S., Hay, J. L., Buckley, T. R., Stein, T. R., \& Berwick, M., et al. (2004). Participation in annual skin cancer screening among women seeking routine mammography. Preventive Medicine 38, 704-712.

15. Foster, P., \& Anderson, C. M. (1998). Reaching targets in the national cervical screening programme: are current practices unethical? Journal of Medical Ethics, 24, 151-157.

16. General Medical Council (2000). Seeking patients' consent: the ethical considerations: GMC.

17. Graham, H. (2004). Tackling inequalities in health in England: Remedying health disadvantages, narrowing health gaps or reducing health gradients? Journal of Social Policy, 33, 115-131.

18. Keough, K. A., Zimbardo, P. G., \& Boyd, J. N. (1999). Who's smoking, drinking, and using drugs? Time perspective as a predictor of substance use. Basic and Applied Social Psychology, 21, 149-164.

19. Kerr, T., Marshall, A., Walsh, J., Palepu, A., Tyndall, M., \& Montaner, J., et al. (2005). Determinants of HAART discontinuation among injection drug users. Aids Care, 17, 539-549.

20. Kim, L. G., Thompson, S. G., Marteau, T. M., \& Scott, R. A. P. (2004). Screening for abdominal aortic aneurysms: the effects of age and social deprivation on screening uptake, prevalence and attendance at follow-up in the MASS trial. Journal of Medical Screening, 11, 50-53.

21. Klingemann, H. (2001). The Time Game: Temporal perspectives of patients and staff in alcohol and drug treatment. Time \& Society, 10, 303-328.

22. Kuiper, H., Miller, S., Martinez, E., Loeb, L., \& Darney, P. (1997). Urban adolescent females' views on the implant and contraceptive decision-making: A double paradox. Family Planning Perspectives, 29, 167-172.

23. Lantz, P. M., Weigers, M. E., \& House, J. S. (1997). Education and income differentials in breast and cervical cancer screening - Policy implications for rural women. Medical Care, 35, 219-236.

24. Levin, B. W., \& Schiller, N. G. (1998). Social class and medical decision making: a neglected topic in bioethics. Cambridge Quarterly of Healthcare Ethics, 7, 41-56.

25. Luszczynska, A., Gibbons, F. X., Piko, B. F., \& Tekozel, M. (2004). Self-regulatory cognitions, social comparison, and perceived peers' behaviors as predictors of nutrition and physical activity: A comparison among adolescents in Hungary, Poland, Turkey, and USA. Psychology \& Health, 19, 577-593.

26. Marshall, T. (2005). Informed consent for mammography screening: modelling the risks and benefits for American women. Health Expectations, 8, 295-305.

27. Marteau, T., \& Kinmouth, A. (2002). Screening for cardiovascular risk: public health imperative or matter for individual informed choice? British Medical Journal, 325, 78-80.

28. Marteau, T. M., Dormandy, E., \& Michie, S. (2001). A measure of informed choice. Health Expectations, 4, 99-108.

29. McCaffery, K., Wardle, J., Nadel, M., \& Atkin, W. (2002). Socioeconomic variation in participation in colorectal cancer screening. Journal of Medical Screening, 9, 104-108.

30. McKerlie, D. (1994). Equality or Priority? Utilitas, 6, 25-42.

31. Nagel, T. (2000). Equality. In M. Clayton, \& A. Williams (Eds.), The Ideal of Equality. Basingstoke: Palgrave Macmillan. 
32. National Screening Committee (2000). 2nd Report of the UK National Screening Committee. London: National Screening Committee.

33. Nurmi, J. E. (1987). Age, sex, social-class, and quality of family-interaction as determinants of adolescents' future orientation - A developmental task interpretation. Adolescence, 22, 977-991.

34. Orbell, S., \& Hagger, M. (2006). Temporal framing and the decision to take part in Type 2 diabetes screening: effects of individual differences in consideration of future consequences on persuasion. Health Psychology, 25, 537-548.

35. Orbell, S., Perugini, M., \& Rakow, T. (2004). Individual differences in sensitivity to health communications: Consideration of future consequences. Health Psychology, 23, 388-396.

36. Parfit, D. (1995). Equality or Priority? In M. Clayton, \& A. Williams (Eds.), The Ideal of Equality (pp. 81-125). Basingstoke: Palgrave Macmillan.

37. Parker, M. (2001). The ethics of evidence-based patient choice. Health Expectations, 4, 87-92.

38. Raffle, A. E. (2001). Information about screening - is it to achieve high uptake or to ensure informed choice? Health Expectations, 4, 92-98.

39. Rakovitch, E., Franssen, E., Kim, J., Ackerman, I., Pignol, J. P., \& Paszat, L., et al. (2003). A comparison of risk perception and psychological morbidity in women with ductal carcinoma in situ and early invasive breast cancer. Breast Cancer Research and Treatment, 77, 285-293.

40. Rawls, J. (1972). A Theory of Justice. Oxford: Oxford University Press.

41. Rembold, C. M. (1998). Number needed to screen: development of a statistic for disease screening. British Medical Journal, 317, 307-312.

42. Rothspan, S., \& Read, S. J. (1996). Present versus future time perspective and HIV risk among heterosexual college students. Health Psychology, 15, 131-134.

43. Scanlon, T. M. (1998). What we owe to each other. Cambridge Mass: Harvard University Press, ch.6.

44. Sen, A. (1980). Equality of what? In S. McMurrin (Ed.). Tanner lectures on human values (Vol. 1). Cambridge: Cambridge University Press.

45. Sen, A., \& Williams, B. (1982). Utilitarianism and beyond. Cambridge: Cambridge University Press.

46. Skinner, E. A. (1996). A guide to constructs of control. Journal of Personality and Social Psychology, 71, 549 .

47. Stein, K. B., Sarbin, T. R., \& Kulik, J. A. (1968). Future time perspective - its relation to socialization process and delinquent role. Journal of Consulting and Clinical Psychology, 32, 257-264.

48. Sutton, S., \& Rutherford, C. (2005). Sociodemographic and attitudinal correlates of cervical screening uptake in a national sample of women in Britain. Social Science \& Medicine, 61, 24602465.

49. Tempkin, L. (2000). Equality, priority and the levelling down objection. In M. Clayton, \& A. Williams (Eds.), The ideal of equality. Basingstoke: Palgrave Macmillan.

50. Thornton, H., Edwards, A., \& Baum, M. (2003). Women need better information about routine mammography. British Medical Journal, 327, 101.

51. Waller, B. N. (2002). The psychological structure of patient autonomy. Cambridge Quarterly of Healthcare Ethics, 11, 257-265.

52. Wardle, J., McCaffery, K., Nadel, M., \& Atkin, W. (2004). Socioeconomic differences in cancer screening participation: comparing cognitive and psychosocial explanations. Social Science \& Medicine, 59, 249-261.

53. Whiteford, J. K., \& Whiteford, J. R. (2003). Screening for breast cancer. Annals of Internal Medicine, $138,768-769$.

54. Wilkinson, T. (1996). Dworkin on paternalism and well-being. Oxford Journal of Legal Studies, 16, 433-444.

55. Zimbardo, P. G., \& Boyd, J. N. (1999). Putting time in perspective: A valid, reliable individualdifferences metric. Journal of Personality and Social Psychology, 77, 1271-1288.

56. Zimbardo, P. G., Keough, K. A., \& Boyd, J. N. (1997). Present time perspective as a predictor of risky driving. Personality and Individual Differences, 236, 1007-1023. 